\title{
AS BASES FREIREANAS DA EDUCOMUNICAÇÃO PRESENTES NO PROGRAMA CONEXÕES PERIFÉRICAS
}

\author{
THE FREIREAN BASES OF “EDUCOMMUNICATION” IN THE \\ PERIPHERAL CONNECTIONS PROGRAM
}

\author{
Maria Eleni Henrique da Silva ${ }^{1}$ \\ Isabel Mayara Gomes Fernandes Brasil ${ }^{2}$
}

\begin{abstract}
RESUMO
O artigo expõe o pensamento freireano sobre educação e comunicação, sustentados pela ação dialógica, assinalando as contribuições que serviram de inspiração para a formação do saber educomunicativo. Uma análise realizada da prática educomunicativa do Programa Conexões Periféricas da Rede Cuca/ Prefeitura de Fortaleza, concebida a partir do pensamento de Paulo Freire. A vivência das juventudes do Conexões Periféricas reconhecem pressupostos freireanos em sua prática. A abordagem qualitativa recorreu à pesquisa bibliográfica, documental e de campo, em que foram aplicadas as técnicas entrevistas semiestruturadas, análise de alguns programas e observação participante. A correspondência entre educomunicação e Paulo Freire, encontrada no Conexões Periféricas ocasionou a sistematização dos seguintes fundamentos freireanos: co-laboração, temagerador/ pergunta, tolerância e a versão da educação como um ato político.
\end{abstract}

Palavra-chave: Paulo Freire; Educomunicação; Conexões Periféricas

\begin{abstract}
The article exposes the Freirean thinking about education and communication, sustained by the dialogical action and marks the contributions, which served as inspiration, for the formation of educomunicative knowledge. An analysis of the educomunicative practice of the Cuca/Fortaleza City Hall's Peripheral Connections Program, conceived from the Paulo Freire thoughts. The experience of the youths of the Peripheral Connections recognizes Freirean presuppositions in their practice. The qualitative approach resorted to bibliographical, documentary and field research, in which semistructured interviews techniques were applied, besides the analysis of some programs and participant observation. The correspondence between educommunication and Paulo Freire, found in Peripheral Connections, led to the systematization of the following Freirean foundations: co-laboring, themegenerator/question, tolerance and the version of education as a political act.
\end{abstract}

Keyword: Paulo Freire; Educommunication; Peripheral Connections

\footnotetext{
${ }^{1}$ Doutora em Educação, Universidade Federal da Paraíba. Professora da Universidade Federal do Ceará, do Instituto de Educação Física e Esportes. Coautora. Contato: melenih@hotmail.com

2 Mestranda do Programa de Pós-Graduação em Educação da Universidade Federal do Ceará, Bolsista FUNCAP. Autora. Contato: isabelmayaragf@gmail.com
} 


\section{Revista \\ Debates Insubmissos}

\section{INTRODUÇÃO}

O campo da Educomunicação veio encontrar nas bases freireanas fundamentação para sua existência; sobretudo, no que tange a teoria da dialogicidade de Paulo Freire, que transita entre as propostas de formação humana e pedagógica. Os pressupostos dialógicos estão presentes tanto na dimensão das relações humanas, como na dimensão dos processos educativos. Nesse sentido, é entendido que comunicação dialógica é um elemento intrínseco as duas dimensões (formação humana e pedagógica).

Embora, não se tenha encontrado indícios, na literatura freireana, que faça referência direta ao campo do saber educomunicativo, até porque sua concepção veio após os escritos de Paulo Freire.

Contudo, é possível entrelaçar várias categorias e concepções de Paulo Freire, com a ação educomunicativa. Este artigo se propõe a relacioná-los à experiência formativa das juventudes do Programa Conexões Periféricas.Uma forma de justificar, na prática, o pressuposto orientador, citado acima: a Educomunicação tem referências epistemológica as ideias de Paulo Freire.

O Programa Conexões Periféricas é realizado por jovens alunos da Rede $\mathrm{Cuca}^{3}$, desenvolvido pela Prefeitura de Fortaleza e pela TV Ceará - TVC. Os jovens comunicadores discutem questões relacionadas às juventudes de um modo geral, principalmente, as questões do âmbito da periferia: social, acessibilidade, mobilidade, cultural, gênero, empreendedorismo entre outros assuntos.

Durante a formação em audiovisual até a concepção do produto final, o programa transmitido pela TVC, tem a intenção de oferecer um espaço de vez e voz aos jovens da periferia de Fortaleza e do Brasil, conforme anunciado pelos jovens apresentadores, na abertura do programa ${ }^{4}$ número um, da primeira temporada, realizada em 2015.

Muitos temas são instigantes ao utilizar os pressupostos de Paulo Freire: a relação oprimido e opressor e seus desdobramentos, o Ser Mais, Pedagogia Libertadora, "Ninguém

\footnotetext{
${ }^{3}$ A Rede Cuca é uma rede de proteção social e oportunidades formada por três (Cucas Barra, Mondubim e Jangurussu) Centros Urbanos de Cultura, Arte, Ciência e Esporte (Cucas), mantidos pela Prefeitura de Fortaleza

Atendem, prioritariamente, jovens de 15 a 29 anos, oferecendo cursos, práticas esportivas, difusão cultural, formações e produções na área de comunicação e atividades que fortalecem o protagonismo juvenil e realizam a promoção e garantia de direitos humanos. Retirado do link: https://juventude.fortaleza.ce.gov.br/rede-cuca
}

${ }^{4}$ Disponível em: https://www.youtube.com/playlist?list=PLPwF7flqTgyP0g7wF8YMmQ7IX46pn7asN 
liberta ninguém, ninguém liberta-se sozinho, os homens se libertam em comunhão", a concepção bancária da educação e o obscurecimento do currículo, a relação educador e educando na perspectiva libertadora, "Ninguém educa ninguém, ninguém educa a si mesmo, os homens se educam entre si mediatizados pelo mundo" e tantas outras temáticas.

Diante da complexidade de sua obra, inúmeras categorias temáticas são trazidas por Paulo Freire, e apesar de destacarmos algumas categorias, a fim de relacionar com a problemática desse estudo, é entendido que elas estão interligadas e integradas num universo dialógico. Vários aspectos podem ser claramente relacionados com a iniciativa Educomunicativa, entre elas: comunicação, dialogo, co-laboração, tema-gerador/ pergunta, tolerância e politicidade da educação, co-laboração.

É visto a relevância deste autor, como um dos mais importantes educadores e filósofos, a pensar e dialogar sobre a relação entre a comunicação e educação. Aqui, a proposta é aproximá-lo ainda mais, situando-o no terreno da inter-relação entre as áreas da Educação e da Comunicação, que resultaram na Educomunicação.

No intuito de atender aos objetivos deste estudo e feito a opção pela pesquisa bibliográfica, com a análise de documentos, bem como a realização de entrevista. A perspectiva bibliográfica para analisar alguns pontos em comum entre o pensamento do educador Paulo Freire e o campo da Educomunicação; documental (arquivos dos programas, disponibilizados no youtube e documentos do projeto). Um trabalho que também teve a contribuição, por meio de entrevistas semiestruturada, com o coordenador geral do Programa e Diretor de Comunicação, Rogério Maia, além do acompanhamento durante os encontros formativos, a partir de setembro de 2018, em que foi aplicada a técnica de observação participante.

\section{REFERENCIAL}

Não se pode falar de diálogo, sem falar em comunicação, sem falar em comunhão, em transformação, em educação. Assim, se constitui o encadeamento de ideias dentro da lógica freireana. É compreendido que não dá para ler Paulo Freire separando as categorias temáticas em caixas conceituais. Em Freire, tudo está integrado, conectado. Um pensamento leva a outro, que nos leva um vasto terreno de interpretações, mas todas elas fundamentadas na 
perspectiva do humano como um ser inconcluso, em processo de mudança constante, integrado e mediatizado pelo mundo. E a matriz inspiradora, que se estende por toda sua obra, é baseada no ideal político de transformação da sociedade, na direção para que essa mudança seja uma realidade.

Seguindo essa lógica, na qual parte a compreensão de que todos elementos da obra de Freire estão "juntos e misturados", direcionados a concretização de um sonho revolucionário de transformação social. Entretanto, mesmo tendo aceitado esta concepção integradora, este estudo tenta limitar-se a duas temáticas de Paulo Freire, que considera como centrais: comunicação e educação. Para então, elencar sub-temáticas (categorias), que se relacionam com a proposta educomunicativa, do Programa Conexões Periféricas: diálogo, co-laboração, tolerância e politicidade da educação.

Com meia hora de duração, o programa apresenta as culturas juvenis das periferias de Fortaleza. Os jovens participam de atividades de formação e produção em audiovisual, transmitidos nas tardes de sábados na TVC. Os jovens são selecionados, via edital público, que contém apenas uma restrição: ter entre 18 e 29 anos. Iniciada em março de 2017, a terceira temporada do programa teve um aumento de ofertas de vagas: 60 jovens, sendo 20 por Cuca. A intenção é de aumentar para 120 jovens, nas próximas temporadas, conforme informações do Diretor de Comunicação, Rogério Maia.

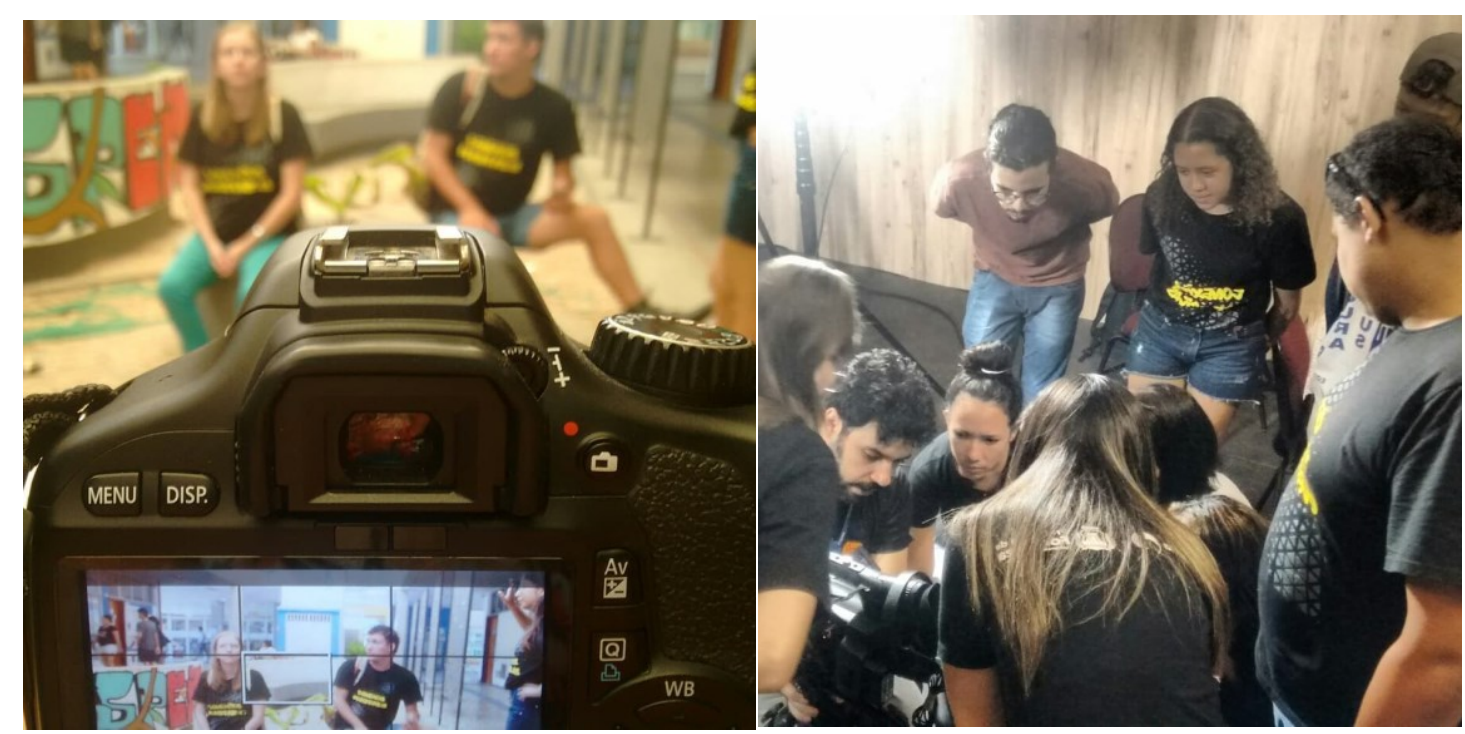




\section{Revista \\ Debates Insubmissos}

${ }^{5}$ Arquivo Pessoal: Registros de momentos da formação na Rede Cuca/ Mondubim (F1: Gravação/ F2: demonstração de como operar a câmera).

O Instituto de Cultura, Arte, Ciência e Esportes, doravante denominado Instituto CUCA, atualmente conhecido por Rede Cuca, são centros urbanos, formados por três equipamentos, mantidos pela Prefeitura de Fortaleza: os Cuca do Jangurussu, Mondubim e Barra do Ceará. Juntos, formam a maior rede de proteção social e de oportunidades para a juventude do Ceará. A localização dos centros baseia-se nos pontos de vulnerabilidade social e econômica, a fim de colaborar para a transformação da realidade local, através do trabalho em prol da não violação dos direitos humanos, fomento às produções locais artísticas e culturais e do acesso as oportunidades de formações. O Conexões Periféricas é uma oportunidade de formação técnica, cidadã e humana.

A partir do próximo tópico, é apresentada a integração entre as categorias do Programa Conexões Periféricas com as seguintes macro-propostas de Paulo Freire: Educação, Comunicação e Diálogo. No desenvolvimento, outras propostas, que procedente dessas, também são relacionadas com o programa em destaque: Co-laboração, Tolerância, Tema gerador/Pergunta e Policiticidade da Educação.

\subsection{Educação, Comunicação e Diálogo}

Um dos indícios da integração das categorias comunicação e diálogo pode ser vista no trecho "a educação é comunicação, é diálogo, na medida em que não é a transferência de saber, mas um encontro de sujeitos interlocutores que buscam a significação dos significados" (FREIRE, 1979, p. 69).

Na ocasião do V Colóquio Internacional Paulo Freire, Accioly (2005) registra que “A comunicação e a educação nasceram e cresceram juntas, tornando-se dependentes uma da outra para que pudessem ocorrer" (p.3).

O novo campo, a Educomunicação, agrega experiências e elementos da inter-relação entre a comunicação e a educação. Torna-se um espaço de intervenção social e

\footnotetext{
${ }^{5}$ Registros fotográficos realizados pela câmera de celular da pesquisadora durante as observações da $4^{\circ}$ temporada do Programa, iniciada em setembro de 2018.
} 


\section{Revista \\ Debates Insubmissos}

interdisciplinar, concentrado na criação e no fortalecimento de ecossistemas comunicativos ${ }^{6}$. Soares (1999, p.9) diz que a Educomunicação é toda ação comunicativa num espaço educativo.

Soares (2006) assinala que é uma nova proposta de pensamento que oferece participação, autonomia e criticidade aos envolvidos. Um campo feito da interseção de dois conjuntos de saberes, que sempre foram próximos. $\mathrm{O}$ autor prefere se referir ao termo campo, e não ciência, por acreditar que a concepção de campo seja um espaço amplo sem intervenções antigas que impeçam novos avanços.

Trata-se, então, de um espaço no qual transversa saberes historicamente constituídos. Como um tabuleiro no qual se lançam pedras para, com elas, construir grandes lances - assim se apresenta esse novo campo. Não importa a origem das peças, assim como não se privilegia quem possa colocá-las ali.Seja qual for o tipo ou a forma de conhecimento, o campo não somente tem condições de recebê-lo, mas, sobretudo, de promover o diálogo com ele e dele com os outros. (SOARES, 2006, p.3)

Paulo Freire, em vários momentos de seus escritos, indica que a matriz dialógica da educação libertadora remete a coerência de que comunicação e educação só existem através do diálogo. "O que caracteriza a comunicação enquanto este comunicar comunicando-se, é que ela é diálogo, assim como o diálogo é comunicativo" (FREIRE, 1979, p. 67).,Nunes et al (2016) assinalam que a noção de comunicação, dentro da perspectiva da pedagogia libertadora, é presente em Extensão ou Comunicação (1979), conforme expresso na citação anterior.

A proposta da comunicação dialógica de Paulo Freire é lembrada por esses autores quando o educador se reporta ao respeito pelo outro, a negação do ajustamento ou acomodação, valorização da integração, do homem como sujeito de suas ações e não como objeto. Accioly (2005) também sintetiza o conceito de comunicação dialógica, sob a ótica freireana:

O modelo dialógico de Paulo Freire baseia-se no respeito pelo outro, não visa acomodação ou ajustamento, mas enfatiza a integração que torna o homem sujeito de suas ações e o afasta da condição de objeto, de dominado, sem vez e sem voz. (ACCIOLY, 2005, p.3).

\footnotetext{
${ }^{6}$ Termo citado pelo filósofo espanhol Jesús Martin-Barbero, que fundamentou essa inter-relação comunicação e educação.
} 
A proposta dialógica presente tanto na educação, quanto na comunicação, às vistas de Paulo Freire é uma relação, acima de tudo, de AMOR. Um amor visto pelas lentes da solidariedade, da humildade, da fé, da confiança e da esperança. "Não há diálogo, porém, se não há um profundo amor ao mundo e aos homens [...]. Sendo fundamento do diálogo, o amor é, também, diálogo". (FREIRE, 1987, p.5).

O amor que é base de muitas coisas, inclusive do diálogo. É preciso notar a força do diálogo, o diálogo como um ato de amor. Como diz Freire em Pedagogia do Oprimido, ao relatar os fundamentos do diálogo: o diálogo é um ato de amor, amor ao mundo e aos homens, ele é o fundamento do diálogo, que gera um ato de coragem, nunca de medo. Um amor que é sinônimo de compromisso com os outros e consigo. É o comprometer-se com a causa de sua libertação. Um compromisso, por ser amoroso é dialógico. Um amor que é o único caminho que leva ao diálogo, que leva criticidade, a conscientização e a transformação.

Para Freire (1987), o diálogo é o encontro dos homens para Ser Mais, feito nas bases da esperança, pois os sujeitos precisam esperar algo do seu quefazer, para tanto é necessário o pensamento crítico, por parte dos sujeitos, para que entendam que não há dicotomia entre mundo-homem, e sim uma relação solidária entre ambos.

Segundo Freire (1987), além do amor, é preciso humildade, não há cabimento para a arrogância, para a autossuficiência, que são incompatíveis com o diálogo. De mãos dadas com o amor e a humildade, a CONFIANÇA, que fazem os sujeitos dialógicos companheiros na pronuncia do mundo. Freire (1987) diz: se falhar a confiança, falhou amor, humildade, fé e a esperança.

Após essas rápidas considerações sobre a aproximação entre a comunicação e a educação, a partir da ótica freireana, este estudo aponta que o diálogo entre essas duas áreas do saber, gerou uma terceira visão, uma prática alternativa com proposta própria. Um campo de relação de e entre saberes, um espaço de transdiscursividade, multidisciplinaridade e pluriculturalidade, sobretudo autônomo. O Programa Conexões Periféricas que tem como fio condutor de sua formação, a Educomunicação, é analisado por meio de determinadas categorias conceituais do pensamento freireano.

\section{DESENVOLVIMENTO}




\subsection{Co-laboração, Tema gerador/Pergunta, Tolerância e Policiticidade da Educação}

A partir das concepções gerais sobre as categorias centrais "Educação", "Comunicação" e "Dialogicidade" de Paulo Freire, este estudo destaca em tópicos, outras sub-categorias temáticas freireanas, para relacioná-las com aspectos da prática educomunicativa do Programa Conexões Periféricas: Co-laboração, Tema gerador/Pergunta, Tolerância,ePoliciticidade da Educação.

\subsubsection{Co-laboração}

O conceito de comunicação como diálogo, segundo Freire, traz à tona a ideia de coparticipação dos sujeitos no ato do pensar. Para Freire (1987), a co-laboração é uma das características que delineiam o perfil da teoria da ação dialógica; portanto, os sujeitos se encontram para a transformação do mundo em co-laboração. Não há espaço para relação de dominação e sim para um encontro para pronúncia do mundo, onde os sujeitos visam a transformação. Nesse sentido, Freire (1987) salienta:

O eu dialógico, pelo contrário, sabe que é exatamente o tu que o constitui. Sabe também que, constituído por um $t u$ - um não-eu -, esse $t u$ que o constitui se constitui, por sua vez, como eu, ao ter no seu eu um $t u$. Desta forma, o eu e o tu passam a ser, na dialética destas relações constitutivas, dois $t u$ que se fazem dois $e u$. (FREIRE, 1987, p. 96).

Dentro da lógica de enxergar a si e o outro, em comunhão, como agente da mudança, Freire reconhece o papel da liderança revolucionária e alerta que sua relação para com as massas se dá pelo princípio da CO-LABORAÇÃO. Um esforço diretivo, que norteie os envolvidos rumo à libertação, sem manipulação, conquistas e adesões. A co-laboração não nega o papel do líder, desde que ela seja revolucionária. Freire reconhece que ela é necessária em todos os níveis de função e responsabilidade e só é possível realizar-se na comunicação. “O diálogo que é sempre comunicação, funda a co-laboração" (p. 96).

Trazendo esse aspecto freireano para a vivência do Conexões Periféricas, pode-se dizer que o programa por ser uma prática educomunicativa, que por sua vez tem bases freireanas, exerce o fazer em co-laboração. O programa conta com uma carga-horária de 9 horas por semana, totalizando em 216 horas, ao final da temporada. Tempo destinado para realização das atividades de formação, produção, prática e vivências. 


\section{Revista}

Debates Insubmissos

Tais atividades são divididas em três ciclos: o primeiro, Ciclo de Estímulos, compreende os encontros teóricos para realização de reflexões sobre os meios de comunicação no Brasil, o processo de produção e difusão das informações, as experiências de comunicação popular (televisão comunitária), a relação entre sociedade, cultura e comunicação, dentre outras temáticas afins.

O segundo, Ciclo de Produção, segue uma sistemática técnica de produção dos programas. Permite que cada Cuca produza um programa, desde o roteiro, elaboração de pauta, gravação e edição do material produzido. Maia (2017) detalha que os jovens passam por uma reunião de pauta, por programa, onde escolhem e elaboram pautas e roteiros.

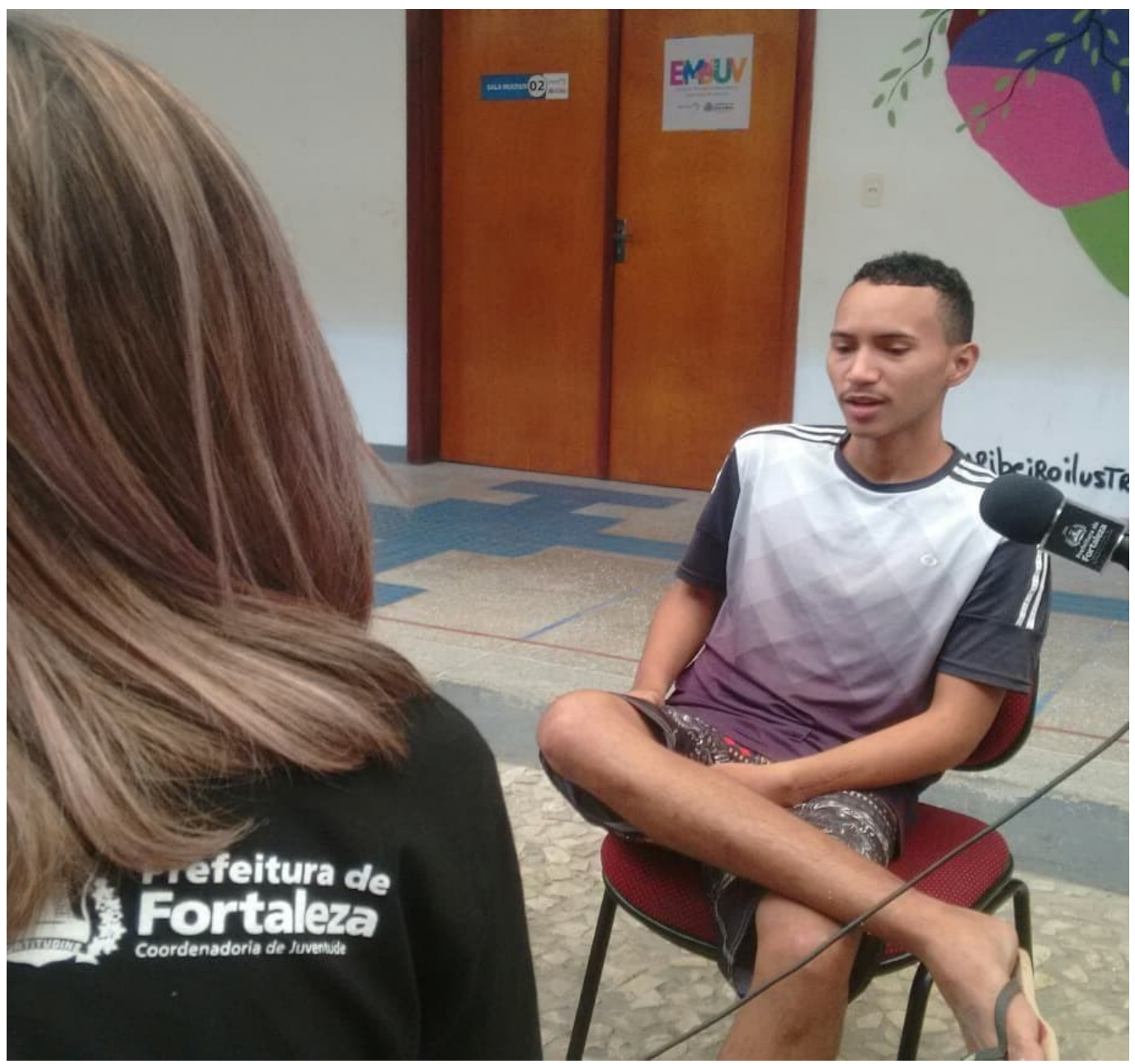

Arquivo pessoal: Simulação entre o grupo de como realizar uma entrevista. 
O Ciclo de Vivências é a terceira e última fase. É a própria condução do programa desde a produção, reportagem, apresentação e edição e a aproximação dos jovens às experiências práticas na TV Ceará. O objetivo é que os jovens acompanhem as atividades de produção de um telejornal, ou programa de entretenimento da emissora.

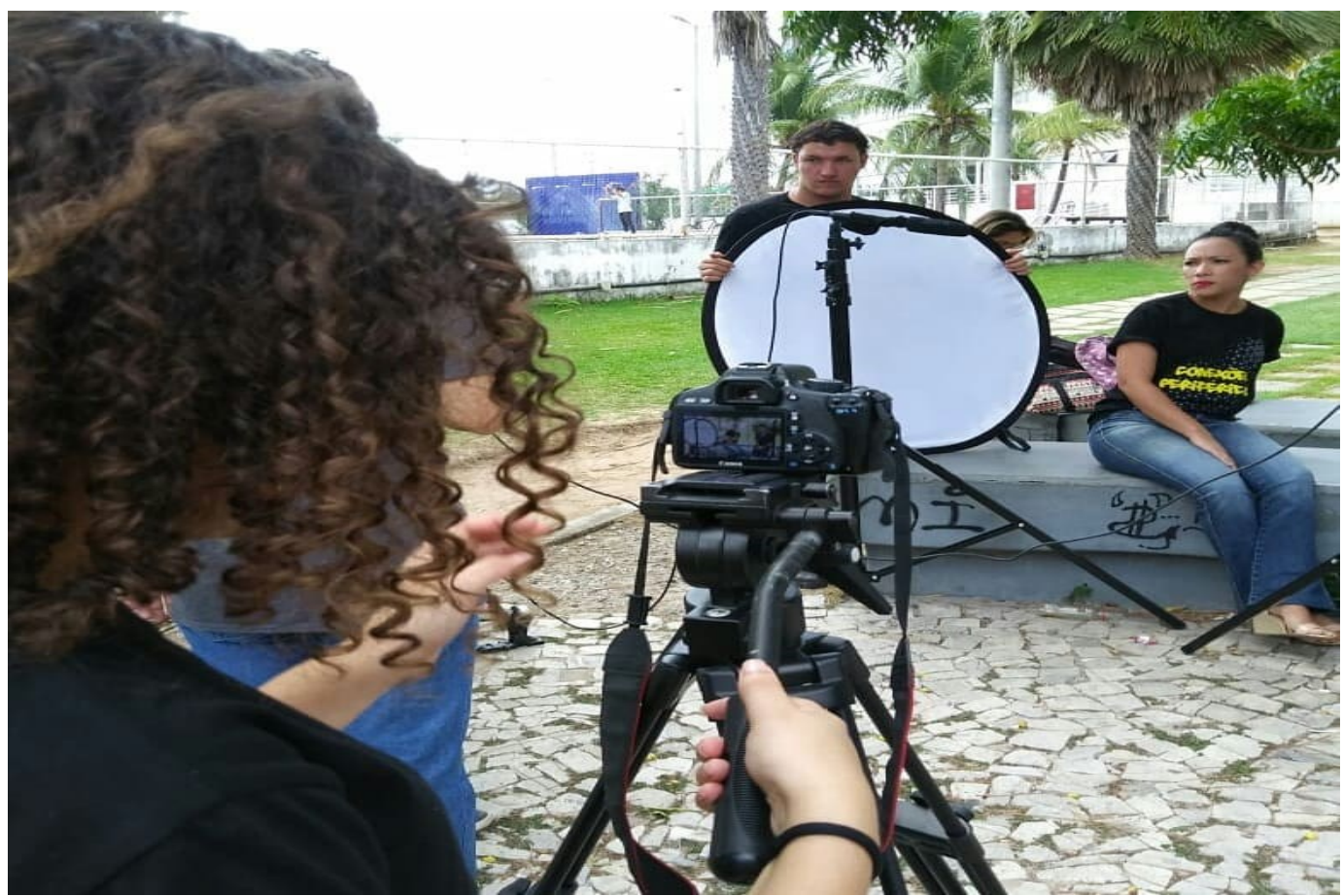

Arquivo pessoal: Momento em que o grupo realizateste para locação da entrevista nas dependências do Cuca/Mondubim.

Durante a formação em audiovisual, os jovens realizam rodízio de funções, o que permite uma ampliação do conhecimento e da prática, autonomia no fazer, sobretudo, remete o espírito colaborativo, onde todos compartilham experiências e aprendizados, construindo um produto: o programa de TV. "Liderados" por um comunicador popular, gestores, técnicos e outros agentes da Rede Cuca, que tem o objetivo de implementar a formação, os jovens conduzem todo o processo, dirigidos por seus professores. A co-laboração também está presente no ato de perguntar. Para Freire, é a pergunta que abre portas para o verdadeiro 
diálogo, que fundamenta as temáticas geradoras de um diálogo, de um encontro, de formações.

\subsubsection{Tema Gerador/ Pergunta}

Freire (1985) também nos traz o quanto de amor e suas virtudes pode-se descobrir no ato de perguntar. É na indagação que processa o pensamento ativo, criativo e crítico. Freire, a partir de uma matriz dialógica, defende uma aprendizagem mediada por perguntas, onde se investigam problemas, na busca por soluções. Para ele, todo conhecimento começa na PERGUNTA.

É a curiosidade que melhora nossa capacidade de pensar, imaginar e criar. Freire nos faz refletir sobre a sociedade das respostas/opiniões. É válida a opinião, mas ela por si só, sem passar pelo crivo da criticidade, não convém. Porque não paramos de dá respostas para tudo e damos mais importância às perguntas? É nelas onde mora a curiosidade, o impulso para o desejo de conhecer e aprender.

Freire (1985) discorre sobre a valorização da pergunta e diz que são elas que nos abrem os olhos para novas dimensões e nos lançam o convite para o diálogo. A verdade se encontra no diálogo, é uma busca, não um resultado. Ela está em parte, em você, em parte, no outro. Faz a reflexão sobre a necessidade de se aprender a começar a perguntar, pois o ensino hoje é resposta e não pergunta. A educação libertadora vem como um ponto de partida para esse exercício de aprender a perguntar.

Partindo da importância da pergunta para qualquer processo formativo, este estudo relaciona com a proposta dos temas geradores, que partem das perguntas aos educandos sobre o que se pode dialogar. Para Freire (1987), o conteúdo da educação libertadora deve partir da situação presente, existencial e concreta; e deve refletir as aspirações do povo, contendo seus anseios, dúvidas, esperanças e temores. Há de haver essa sintonização com o que o homem fala.

A preparação do conteúdo, a partir dos temas geradores, um movimento é um movimento de busca que inaugura o diálogo da educação como prática da liberdade. Uma busca pelo universo temático do povo e de seus temas geradores. Então, o diálogo, inicia-se pela pergunta: o que se pretende dialogar? 
O Conexões Periféricas reconhecendo a pluralidade das juventudes participantes, além de possibilitar o rodízio de funções ao longo do processo, também permite a liberdade de escolha das temáticas a serem abordadas no programa. Tratam de assuntos que circundam as diversas realidades dos jovens, tais como: temáticas propostas e debatidas entres eles, assim como a co-gestão de todo o processo.

\subsubsection{Tolerância}

O Programa Conexões Periféricas é um exercício de políticas públicas e se apresenta como uma iniciativa que oferece aos jovens muito mais que formação audiovisual. "Os jovens aprendem mais do que apertar um botão da câmera, é um processo de construção, conhecimento e respeito à diversidade" (MAIA, 2017).

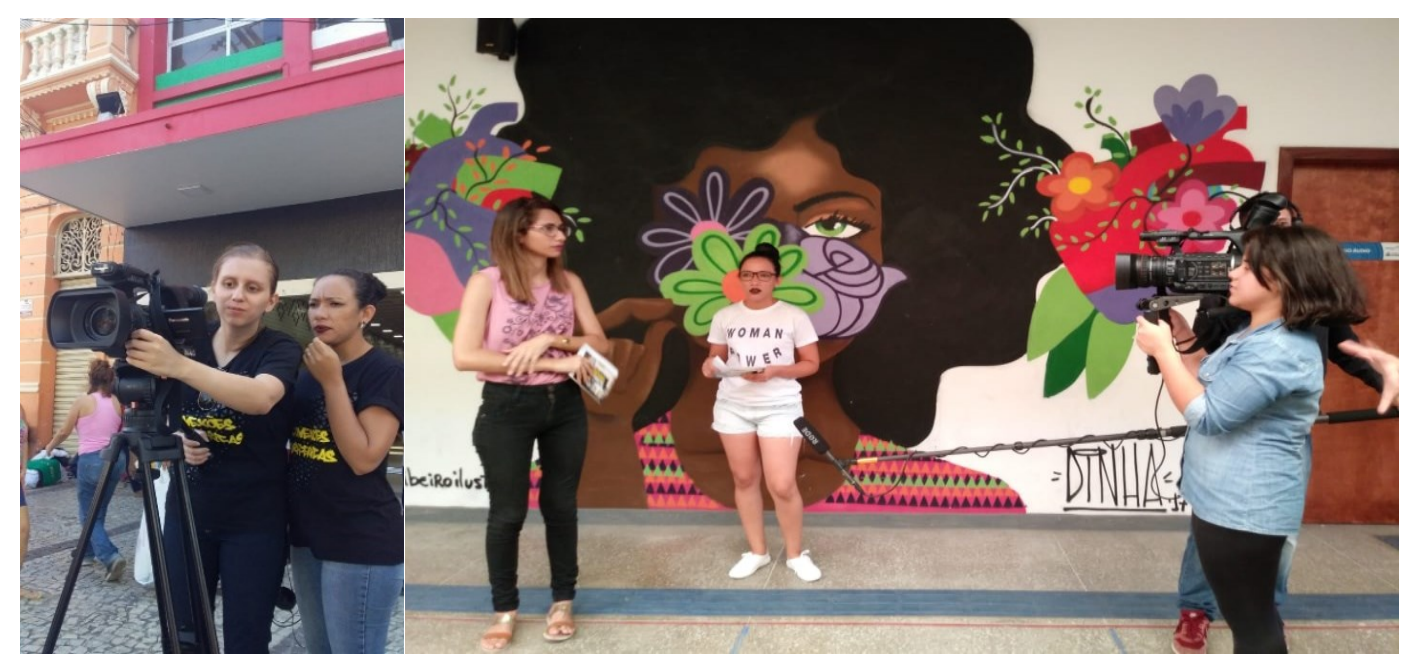

Arquivo pessoal: Formação frente e por trás das câmeras, durante a gravação da abertura do programa e do quadro "Fala, povo!", organizados em rodízio de funções

Maia (2017) explica que a produção de conteúdo, formação em audiovisual, preparação para um possível mercado de trabalho, aprendizagem sobre comunicação popular e democrática são objetivos da realização do Conexões Periféricas, pela Rede Cuca. Contudo, a proposta de respeito à diversidade está implícita ao longo de todo o processo.

Direitos Humanos e Comunicação integram um conjunto de diretrizes institucionais da Rede CUCA, que compreende uma rede de proteção social e oportunidades voltados à promoção de políticas públicas destinadas, especialmente, aos jovens. Jares (2002) concorda 
que os direitos humanos é um marco regulador da convivência, pois todo convívio é regido por normas e valores e ele assegura que a Declaração Universal dos Direitos Humanos é o maior código regulador da conivência democrática. Ao falar sobre a Pedagogia da Convivência, Jares (2008) aponta como um dos marcos que incidem na convivência é a aceitação da diversidade. Segundo ele, a convivência é o aprendizado da conjugação da relação entre igualdade e diferença.

Quanto à convivência vista como uma aceitação da diversidade, Freire (2004) traz a tolerância como a base para agir com o diferente. Freire parte do diálogo amoroso, corajoso e humilde, baseado no respeito ao diferente. Um diálogo, onde o sentido de tolerância afasta-se da postura condescendente ou indulgente de A para com B, longe da compreensão alienada de favor do tolerante com o tolerado, como se o tolerante fosse feito de uma benevolência que lhe dava superioridade para tolerar o tolerado, inferior, digno de ser perdoado e de ser grato para com o tolerante. Não. Não é desta convivência com o diferente que Freire acredita.

A TOLERÃNCIA é a qualidade de conviver com o diferente, porém livre da postura condescendente, da ideia de favor a outro, da inferioridade. Para Freire (2004), a tolerância é uma virtude da convivência humana. "Mas ainda, na tolerância verdadeira não há propriamente o ou a que tolera e o ou a que é tolerado (a). Ambos se toleram" (p. 24). A tolerância virtuosa não exige concordância com aquilo ou com quem tolero, apenas demanda o respeito pelo diferente, que não o negue por ser diferente, onde, na sua experiência, aprendamos com o diferente. Essa virtude é uma instância do homem, a ser criada e cultivada por nós. A ausência dela é distorção viciosa.

Durante a execução do Programa, em todas suas fases a proposta do ser tolerante é vital para a sobrreevivência do projeto. Sem ela, não é possível reconhecer a pluralidade que existe em cada sujeito. Não é possível sair da acomodação e experimentar outras funções, onde o jovem tem de confiar e de acreditar no potencial e no esforço do próximo que assumirá a função vaga. Não seria possível entrar num consentimento a respeito das pautas a serem trabalhadas pelo Programa. Não seria possível o básico, o respeito ao próximo. A tolerância é uma virtude promotora da educação como um ato político. Sem ela é impossível exercer política tendo como meio a educação. 


\section{Debates Insubmissos}

Revista

\subsection{Educação e Educomunicação: ato político}

Outro posicionamento inerente à produção e à trajetória de Paulo Freire é a visão da educação como um ato político. Em Medo e Ousadia, Freire ressalta a grande descoberta: "a educação é política! Depois de descobrir que também é um político, o professor tem de se perguntar: "Que tipo de política estou fazendo em classe?[...] Essa 'coisa' é o projeto político, o perfil político da sociedade, o 'sonho' político" (p. 60), ou seja, educar é manter ou rebelar o status quo.

Para Freire (1986) esse é o grande desafio do professor libertador, o de conciliar a prática do ensino com a opção política. Ainda sobre a politicidade, Freire incorpora essa dimensão política da educação em seus textos e ações.

Agora, (1986) eu digo que, para mim, a educação é política. Hoje, digo que a educação tem a qualidade de ser política, o que modela o processo de aprendizagem. A educação é política e a política tem educabilidade (p.60).

Como Paulo Freire foi uma das inspirações da Educomunicação, base da formação do Conexões Periféricas, a dimensão política da educação jamais poderia ser esquecida dentro da proposta desse artigo.

A fala de Soares (2006) é pertinente ao perceber que a Educomunicação tem como a ‘ação' seu elemento inaugural. Além disso, reconhece como um campo de ação política, no meio dessa inter-relação entre comunicação e educação, há um lugar de encontro, que debate sobre o prisma da "diversidade de posturas, das diferenças e semelhanças, das aproximações e distanciamentos" (p.4). Em decorrência disso, Soares (2006) aponta a transdiscursividade, a multidisciplinaridade e a pluriculturalidade como aspectos que compreendem a dimensão política da Educomunicação.

Mas não só. É um espaço político entendido também como campo de ação prática. [...] A ação que se desenvolve nesse campo de multirrelaçãoé política porque, essencialmente, ela se dá num espaço de realizações. Isto é: de atualização ou concretização de projetos que nascem dos sonhos e/ou necessidades dos grupos sociais em processo de formação e organização. (SOARES, 2006, p.4)

Tendo em vista a relevância da carga política na prática educomunicativa, é ressaltado a responsabilidade da carga política do Conexões Periféricas. Ao oportunizar a fala dos jovens, trazendo suas visões de mundo, seus anseios, suas esperanças e desejos, suas 
linguagens, suas formas de fazer acontecer, o programa possibilita aos jovens uma alternativa de protestarem o status quo.

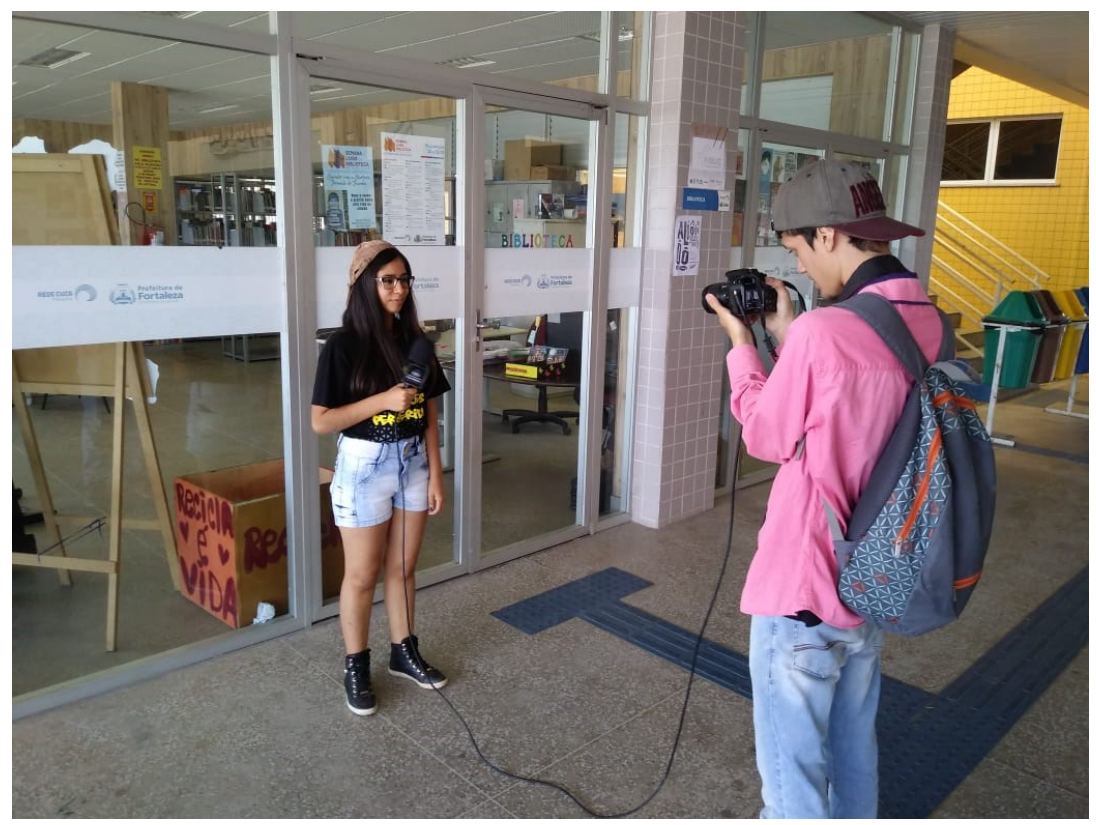

Arquivo pessoal: Gravação externa realizada pelos jovens comunicadores

Pensar, criar e divulgar ações dos jovens das periferias de Fortaleza, por meio de um programa de políticas públicas, configura-se como um ato político, que questiona, denuncia, desvela o que se quer esconder, põe em vista a participação dos jovens para com a política e diversas realidades sócio-culturais, expressos em reportagens de um programa de TV, divulgado na internet e em canal aberto, oficial do Governo do Estado do Ceará- TVC.

\section{4- CONCLUSÃO}

O programa Conexões Periféricas, como uma prática formativa em audiovisual, de base educomunicativa, é um exemplo de que os pressupostos freireanos são atuais e benéficos para a formação pedagógica e humana. Conforme pontuado, o programa é exemplo do exercício do diálogo, amor, confiança, fé, humildade, esperança, co-laboração e tolerância. É um espaço onde a dimensão política da educação é latente, desde a escolha das pautas até a transmissão na Tv, possibilitando aos jovens uma expressão da cidadania (participação), segundo os ensinamentos do mestre da educação, Paulo Freire. 
Freire (2004) defende o uso dos recursos audiovisuais na pedagogia aliada à leitura crítica da realidade. A prática educativa progressista coerente para Freire é aquela que vincula os conteúdos ao contexto social e político, ou seja, auxilia desocultar a razão dos problemas sociais. Acreditando em uma pedagogia que encara os meios não mais como meios de transmissão, Freire exemplifica o alcance do vídeo no processo de aprendizagem:

\begin{abstract}
Mais do que entreter, o vídeo deve ser um objeto desafiador. A prática educativa como processo de conhecimento e não como processo de transmissão de conhecimento é uma coisa linda, porque enquanto o educador reconhece o objeto proposto, o educando reconhece o objeto no processo de conhecimento que o educando faz, quer dizer, no fundo é um ciclo de conhecer, que inclusive confirma o conhecimento. Esse processo é de uma indiscutível boniteza. (FREIRE, 2004, p. 175.).
\end{abstract}

É nesse sentimento otimista, de crer que a Educação está bem acompanhada ao lado da Comunicação que finalizamos esta reflexão sobre as bases freireanas na Educomunicação. Sabemos que podem ser feitas outras conexões entre a literatura freireana e a Educomunicação.

O próprio programa analisado também remete a outras análises que exigem mais tempo e espaço para discussão. Evidenciamos a base dialógica da educação e da comunicação, bem como os outros aspectos citados para registrar que a Educomunicação é um campo de AÇÃO, AMOR, DIÁLOGO, COLABORAÇÃO, TOLERÂNCIA E POLÍTICA.

\title{
REFERÊNCIAS
}

ACCIOLY, Denise Cortez da Silva. Educação e Comunicação na perspectiva de Paulo Freire: a questão da mídia na prática docente. In: V Colóquio Internacional Paulo Freire - Recife, 2005, p.01-12.

FREIRE, Paulo; FAUNDEZ, Antonio. Por uma pedagogia da pergunta. v.15 - Rio de Janeiro: Paz e Terra, 1985.

FREIRE, Paulo. Pedagogia do oprimido. 17ª ed. Rio de Janeiro: Paz e Terra, 1987.

FREIRE, Paulo. SHOR, Ira. Medo e Ousadia: o cotidiano do professor. ed. Rio de Janeiro: Paz e Terra, 1986.

FREIRE, Paulo. Pedagogia da tolerância. São Paulo: Editora UNESP, 2004. 
PERUZZO, Cecília Krohling. Ideias de Paulo Freire aplicadas à Comunicação popular e comunitária. Revista Famecos-Mídia, Cultura e Tecnologia. Porto Alegre, v. 24, n.01, p. 01-16, jan./ fev./ mar./ abr. 2017

SOARES, Donizete. Educomunicação - O que é isto? Gens, Instituto de Educação e Cultura, 2006.

em:http://portalgens.com.br/baixararquivos/textos/educomunicacao_o_que_e_isto.pdf.

Acesso em: 05 março 2017.

SOARES, Ismar de Oliveira; MACHADO, Elliany Salvierra. Educomunicação: ou a emergência do campo de inter-relação. In: INTERCOM, p. 01-09, Comunicação/ Educação. 1999.

JARES, Xesús R. Educação para a Paz: sua teoria e sua prática. 2. ed. Porto Alegre: Artmed, 2002.

JARES, Xesús R. Pedagogia da convivência. São Paulo: Editora Palas Athena, 2008.

MAIA, Rogério. Entrevista concedida a autoria deste projeto de pesquisa. Fortaleza, 6 de janeiro e de fevereiro de 2017. [Rogério Maia, Coordenador de Comunicação da Rede Cuca e Gestor do Conexões Periféricas].

NUNES et al. Comunicação e Educação: Bases Epistemológicas Fundamentadas na Perspectiva Dialógica de Paulo Freire. In: Intercom - XXXIX Congresso Brasileiro de Ciências da Comunicação. São Paulo: Sociedade Brasileira de Estudos Interdisciplinares da Comunicação, p. 1- 15, set., 2016.

Submetido em: 19/12/2018

Aprovado em: 06/02/2019 